\title{
Social stratification, social capital and cultural practice in the UK
}

DOI:

$10.4337 / 9780857935854.00006$

Link to publication record in Manchester Research Explorer

\section{Citation for published version (APA):}

$\mathrm{Li}$, Y., Savage, M., \& Warde, A. (2015). Social stratification, social capital and cultural practice in the UK. In The Handbook of Research Methods and Applications on Social Capital (pp. 21-39). Edward Elgar Publishing Ltd. https://doi.org/10.4337/9780857935854.00006

\section{Published in:}

The Handbook of Research Methods and Applications on Social Capital

\section{Citing this paper}

Please note that where the full-text provided on Manchester Research Explorer is the Author Accepted Manuscript or Proof version this may differ from the final Published version. If citing, it is advised that you check and use the publisher's definitive version.

\section{General rights}

Copyright and moral rights for the publications made accessible in the Research Explorer are retained by the authors and/or other copyright owners and it is a condition of accessing publications that users recognise and abide by the legal requirements associated with these rights.

\section{Takedown policy}

If you believe that this document breaches copyright please refer to the University of Manchester's Takedown Procedures [http://man.ac.uk/04Y6Bo] or contact uml.scholarlycommunications@manchester.ac.uk providing relevant details, so we can investigate your claim.

\section{OPEN ACCESS}




\section{Social stratification, social capital and cultural practice in the UK Yaojun Li, Mike Savage and Alan Warde}

\section{INTRODUCTION}

Over the past few decades there has been increasing examination of the role of social and cultural processes in the generation of social inequalities (Bennett et al., 2009; Le Roux et al., 2008; Li et al., 2008). The dominant view at the end of the twentieth century was that in contemporary post-industrial Western societies the effects of class on socio-cultural practices and identities had faded. The grounds for such conclusions were various, including individualization, post-industrial occupational transition, the emergence of new forms of social engagement, and the reworking of cultural identities and transformation of the cultural landscape. Nevertheless, qualitative investigations continued to throw up evidence of powerful class differences in cultural practices (Skeggs, 1997; Charlesworth, 2000; Savage et al., 2001, 2005). These results were not, however, replicated in analysis of large-scale survey data which, while tending to unearth the apparently benign phenomenon of cultural omnivorousness, found this to be strongly associated with education, not with class (Chan and Goldthorpe, 2007). There has also been much research in social capital, especially in the last two decades, showing considerable class effects (Hall, 1999; Li et al., 2003, 2005, 2008). But there has been little research linking class, social capital and cultural practice. In this analysis we seek to make a contribution to this by providing evidence of a close relationship between social and cultural capital, both underpinned by processes of social stratification as indicated by people's social mobility trajectories.

We begin by reflecting on recent developments in two competing approaches to class analysis: 'the employment aggregate approach' (Crompton, 1998), and 'the cultural class analysis' (Atkinson, 2010). We maintain that it is possible to advance a synthesis which offers a distinctive perspective to debate about classlessness, focusing on the relationship between patterns of social mobility and socio-cultural practices. The second part of the chapter introduces our data, the Cultural Capital and Social Exclusion survey, and explains our methods and procedures. The third section examines the clustering of socio-cultural practices in the UK, demonstrating the close associations between the two domains of practices and the clear divisions between those pursuing 'legitimate culture', 'commercial culture' and more domestic entertainment centred on watching television. This is a necessary preliminary step to the analysis undertaken in the next section to determine how socio-cultural practices are associated with the cumulative social advantages and disadvantages embedded in people's class mobility trajectories, as well as with parental cultural characteristics.

\section{File supplied to Li - Not for distribution}




\section{Handbook of research methods and applications in social capital}

\section{THEORETICAL ISSUES}

In the classic era of class analysis from the 1950s to the early 1970s, the focus was on material inequalities and political alignments. Sociologists uncovered extensive evidence of a significant relationship between class and a vast array of life chances and life choices including sociability and cultural practices. Weberian sociologists such as David Lockwood and John Goldthorpe pursued sophisticated projects examining how class identities were rooted in the milieu of neighbourhood and work relations (Lockwood, 1966; Bulmer, 1975; Goldthorpe, 1987). The genesis of British cultural studies, especially those institutionalized in the Birmingham Centre for Contemporary Cultural Studies, focused on the class relations embedded in the dominant and the subordinate cultural forms (Willis, 1977; Hebdige, 1979). Educational sociology established a powerful role for cultural competence based on class which gave middle-class children a significant advantage in the race for credentials.

Between the early 1980s and the late 1990s the study of the relationship between class and cultural practices became more marginal. The reasons for this were manifold and have been widely rehearsed: the transformation of the occupational structure with de-industrialization and the growth of the service sector (Lash and Urry, 1987), educational reform and the expansion of higher education, and the meshing of affluence, freer markets and global consumer culture (Bauman, 1998). Moreover, other social divisions - gender and ethnicity in particular - attracted more attention as mechanisms of inequality. These structural changes coincided with influential statements regarding the erosion of collective class cultures and the emergence of individualization (Beck, 1992; Giddens, 1991). Others diagnosed a transformation in both the form and the structure of cultural activity, predicting the disappearance of the association between taste cultures and class as hierarchical cultural boundaries dissolved (Beck, 1997). Postmodern culture obviated social classification. 'The end of class' became a popular theme (Pakulski and Waters, 1996).

The claim of classlessness was always contested by structurally oriented sociologists who insisted on the importance of class analysis. Goldthorpe and his colleagues (Goldthorpe, 1987; Erikson and Goldthorpe, 1992; Goldthorpe and Mills, 2008) demonstrated persistent class inequalities in social mobility over time and across nations. However, in broader terms, this paradigm did not undermine the dominant view on the waning importance of class in theoretical circles partly because of its sophistication in mobility analysis. Another reason may be that even though the Goldthorpe class schema has proved its worth in the study of social mobility in Britain and other countries, it did not show much relevance for the study of cultural practices. Indeed, Chan and Goldthorpe (2007: 523) came to the conclusion that it is status and education, not class, that best predict cultural participation, thereby highlighting the restricted relevance of class in complex contemporary cultural relations.

By contrast, 'cultural class analysis' picks up on the changing context of the early twenty-first century and has become increasingly attractive to scholars. This view holds that class is still important in understanding socio-cultural practice. There is increasing recognition of the growing income inequalities, driven especially by the mushrooming fortunes of the very richest groups (Savage and Williams, 2008). Income inequalities have been seen as crucial drivers of poor health and well-being (Wilkinson and Pickett, 2009).

\section{File supplied to Li - Not for distribution}


There have been powerful critiques of the individualization thesis by those pointing to the way that only middle-class groups, with economic, social and cultural resources, are able to act as effective strategic and reflexive agents (Skeggs, 2004; Ball, 2003; Savage, 2000). This argument draws critically on the sociological thinking of Pierre Bourdieu which has helped recharge a sociological concern with the way that cultural processes are complicit with forms of social inequality (Silva and Warde, 2010).

We therefore witness two different paradigms for the analysis of stratification, with considerable tension between them: the Weberian perspectives on the importance of class in social reproduction but not in cultural consumption, and Bourdieusian emphasis on the accumulation, conservation and transmission of class advantages in social, cultural and economic capitals (with all three capitals rooted in the economic sphere). However, we can establish some common ground, as an aspect of reasserting the need to understand processes sustaining the persistent experience of class divisions which qualitative research has revealed (see also Savage et al., 2013). This suggests an approach which can recognize class as an emergent effect of a combination of resources or assets but which does not dispense with, ignore or devalue mechanisms arising from economic factors such as ownership, wealth and employment (Bourdieu, 1987; Sorensen, 2000; Savage et al., 2005). It requires much inventiveness to clarify the complex interdependence of the different types of resources ('capitals' in the terms of Bourdieu) underpinning contemporary inequalities and also appropriate data to trace intergenerational transmission of class privilege in a way that could combine aspects of a Bourdieusian focus on inheritance and transmission with the 'employment aggregate' approach, which insists on the need to understand the resources that affect patterns of class mobility. Aspects of both these approaches help capture the social complexity of the mechanisms (and hidden injuries) of class differentiation (Skeggs, 1997).

A key step in developing a rigorous class analysis of cultural practices involves a reconsideration of the concept of cultural capital, initially devised by Bourdieu as an explanation for the educational success of middle-class children (Bourdieu and Passeron, 1973) and later widely used to understand the patterning of cultural consumption in explanations of the operation of the culture industries and social stratification (Robbins, 2005). This multiple deployment has led to some suspicion regarding analytic precision (Lamont and Lareau, 1988; Prieur and Savage, 2011), while scholars in cultural studies have questioned its empirical value given objective changes in cultural practice, in particular the revaluation of popular culture and the consequential undermining of hierarchical classifications of cultural forms and content (Fiske, 1989). The capacity for a competent command of legitimate culture to deliver prestige, power and wealth, which was the core claim of Bourdieu's critical theory, was considered to have been undermined by radical cultural change.

Our analysis builds on prior research that seeks reconciliation between elements of the 'cultural class analysis' and the 'employment aggregate' approaches. An important means of doing this is through examining the relationship between structural class relations and forms of social and cultural capital, which will allow us to assess how far social involvement and cultural practice are related to each other and are rooted in class structural inequalities. The sociological literature still contains few persuasive studies either of the association between social capital and cultural consumption or of the underlying structures. It is often argued that, at the general level, whom one knows or admires will

\section{File supplied to Li - Not for distribution}


affect one's tastes (Lin, 2001). However, this is corroborated in Britain only in case studies of small group interactions where the two domains are found hard to distinguish, suggesting that the two forms are symbiotic (Southerton, 2002). One reason is the difficulty of getting suitable measures of social and cultural participation for the general populations (Erickson, 1996). Quantitative studies of cultural taste rarely have access to data on social networks. Another reason is due to the difficulty in measuring social capital, as the definitions by Bourdieu (1986), Coleman (1990) or Putnam (2000) do not lend themselves to easy operationalization using social surveys. Among the studies that have a bearing on this, the closest is that by Chan and Goldthorpe (2007) who used the respondent's best friend's class as the indicator of social status, rather than of social capital. Whilst the best friend's class closely approximates that of the respondent on the principle of homophily, this approach makes little allowance for the richness of social interactions such as the density, the mean status or the diversity of social ties, nor their effects on taste formation.

A further problem in achieving reconciliation concerns the widely used concept of cultural omnivorousness. The omnivore thesis says that people in higher social positions not only consume highbrow cultural items, they enjoy popular culture as well and to a similar extent. Developed by American cultural sociologist Richard Peterson, it has been increasingly taken up by those within 'employment aggregate' perspectives. Chan and Goldthorpe (2007) give support to the omnivore thesis, in part as a means of distancing themselves from Pierre Bourdieu's homological perspective. Many other scholars have also demonstrated the general association between high socioeconomic status and omnivorousness for many affluent societies (Peterson, 1997). However, as Peterson (2005) points out, omnivore studies tend to concentrate on a volume measure, namely, how many types and genres of culture people like, partly because it is easier to operationalize. Yet it is the composition of tastes that is at the core of the thesis, and ignoring it loses the sense that omnivores, despite ranging widely across cultural forms, may still have a specific command of legitimate culture as a particularly valuable asset (Warde, 2011). Indeed if it was simply a matter of volume of tastes, one would be inclined to conclude that culture itself was inert, that items would have no symbolic significance in themselves in terms of either hierarchical or horizontal distinctions, and that being unusually energetic or randomly eclectic would be enough. However, if the powerful have a disproportionate propensity to participate in highbrow as well as midor lowbrow culture, one might ask whether they have an equal propensity for highbrow and lowbrow culture, and whether the powerless would/could have a similar propensity. In other words, is omnivorousness a true and adequate description, or is it a disguise for privilege?

We report below on a rigorous study of the relationship between mobility trajectory, social capital, parental culture and different types of cultural practice. We use a measure of class which incorporates intergenerational social mobility for a fuller understanding of the structural effects on socio-cultural engagement than that permitted by the use of current class alone. In addition, we have rich information on cultural resources in families of origin, including the education of both parents and their cultural preferences. We also have a sophisticated set of measures of social capital derived from Lin's (2001) position generator approach. By using these measures in a single study we are able to clarify the role of class, social connection, family influence and cultural practice in reproducing

\section{File supplied to Li - Not for distribution}


inequality in contemporary societies like the UK. We conclude that cultural competence oils the accumulation of privilege across generations and among people with different social networks and that class underpins socio-cultural practice.

\section{DATA AND METHODS}

We use data from the Cultural Capital and Social Exclusion (CCSE) survey. This is a national representative sample for people aged 18 or above who are resident in private households in the UK. It used a stratified clustered random procedure and achieved a sample of 1564. Checks on the socio-demographic characteristics and the civic engagement profiles of the sample against other data such as the well-known British Household Panel Survey (BHPS) indicate that the survey's main attributes are comparable with these (Thompson, 2004; Li et al., 2008: Appendix Table 1 and note 3).

The CCSE has unusually rich information on socio-cultural capital, parental resources and the respondent's personal attributes. ${ }^{1}$ With regard to cultural capital, it asks 190 questions on cultural taste, knowledge and participation (Q86-Q275 available at http://www.esds.ac.uk/doc/5832/mrdoc/pdf/5832userguide.pdf). Building on earlier findings that cultural practices are more socially differentiated than tastes (Bennett et al., 2009), we focus on the fifty variables which pertain to cultural practices in the survey. These include questions on leisure activities, eating preferences, and listed books and paintings that the respondents have read or seen over the previous year. Grouping some of the questions, we obtained 23 ordinal variables on cultural practices as shown in Table 2.1.

The CCSE also contains unusually rich data on parental socio-cultural resources. In addition to data on the primary earner's (usually father's) class at respondent's age of 14-16, it has information on both parents' educational qualifications and their cultural pursuits or hobbies such as reading, attending classical or popular music concerts, participating in sport, cooking, gardening and DIY, which are directly relevant to the question of cultural transmission. Although there is a large amount of social mobility research in Britain (Goldthorpe, 1987; Goldthorpe and Mills, 2008; Li and Devine, 2011, 2014; Devine and Li, 2013), there is rather limited research linking parental education or cultural pursuits to the respondent's cultural practice (though see Scherger and Savage, 2010). The data on the respondent's social networks are especially valuable based on Lin's (2001) 'position generator' procedure (Q330-340 on the website cited above). It asks the respondents whether they know socially anyone who has any of these jobs:2 (1) Secretary; (2) Solicitor; (3) Clerical officer in national or local government; (4) Bus or coach driver; (5) Bank or building society manager; (6) Factory worker; (7) University/college lecturer; (8) Electrician; (9) Nurse; (10) Postal worker; and (11) Sales or shop assistant. This list of occupations is rather suitable to the British context in that they all have a significant number of people working in them and located in different class positions, and they have different gender profiles. The respondents could nominate any of them as their social contacts. From this we derived measures of volume, range and position of respondents' contacts. Volume is the number of contacts, ranging from 0 to 11 . Range refers to the distance between the highest and the lowest scores of the contacts' positions on the basis of the Cambridge Social Interaction Scale

\section{File supplied to Li - Not for distribution}




\section{Handbook of research methods and applications in social capital}

Table 2.1 Latent scores for items of the different types of cultural practice

\begin{tabular}{|c|c|c|c|c|c|c|}
\hline \multirow[b]{2}{*}{ Legitimate activity } & \multirow[t]{2}{*}{$\begin{array}{l}\text { No. of } \\
\text { categories }\end{array}$} & \multicolumn{3}{|c|}{$\begin{array}{l}\text { Cross-loadings of latent } \\
\text { variables }\end{array}$} & \multirow[t]{2}{*}{$\begin{array}{c}\text { Loading } \\
\lambda_{i}\end{array}$} & \multirow[t]{2}{*}{$\begin{array}{c}\text { SE of } \\
\lambda_{i} \\
\end{array}$} \\
\hline & & & & & & \\
\hline Frequency going to museums & 4 & 0.775 & 0.234 & -0.302 & 0.822 & 0.012 \\
\hline Frequency going to operas & 4 & 0.717 & 0.042 & -0.246 & 0.705 & 0.024 \\
\hline Frequency going to concerts & 4 & 0.766 & -0.048 & -0.271 & 0.711 & 0.019 \\
\hline Frequency visiting stately homes & 4 & 0.701 & 0.108 & -0.260 & 0.690 & 0.016 \\
\hline Frequency going to musicals & 4 & 0.596 & 0.143 & -0.148 & 0.658 & 0.018 \\
\hline Frequency going to theatres & 4 & 0.730 & 0.225 & -0.273 & 0.777 & 0.015 \\
\hline Frequency going to art galleries & 4 & 0.750 & 0.223 & -0.312 & 0.806 & 0.013 \\
\hline Belonging to art clubs & 2 & 0.410 & -0.112 & -0.113 & 0.366 & 0.043 \\
\hline No. of active civic memberships & 5 & 0.513 & 0.156 & -0.211 & 0.504 & 0.023 \\
\hline No. of 6 listed books read & 6 & 0.582 & 0.143 & -0.142 & 0.594 & 0.019 \\
\hline Quintile of books read last year & 5 & 0.520 & 0.067 & -0.095 & 0.528 & 0.022 \\
\hline No. of 7 listed paintings seen & 7 & 0.624 & 0.104 & -0.204 & 0.616 & 0.017 \\
\hline \multicolumn{7}{|l|}{ Commercial activity } \\
\hline Frequency going to cinemas & 4 & 0.382 & 0.681 & -0.264 & 0.762 & 0.019 \\
\hline Frequency going to pubs & 5 & 0.056 & 0.529 & -0.058 & 0.417 & 0.027 \\
\hline Frequency going to rock concerts & 4 & 0.285 & 0.617 & -0.243 & 0.650 & 0.025 \\
\hline Frequency going to night clubs & 4 & -0.137 & 0.799 & -0.075 & 0.478 & 0.028 \\
\hline Frequency eating out & 5 & 0.260 & 0.479 & -0.131 & 0.531 & 0.025 \\
\hline Whether doing sports & 2 & 0.382 & 0.575 & -0.379 & 0.789 & 0.022 \\
\hline Internet activities excl. shopping & 5 & 0.332 & 0.522 & -0.297 & 0.625 & 0.025 \\
\hline Frequency going to gym & 6 & 0.311 & 0.583 & -0.335 & 0.721 & 0.021 \\
\hline Frequency jogging & 6 & 0.175 & 0.662 & -0.307 & 0.634 & 0.030 \\
\hline \multicolumn{7}{|l|}{$T V$ watching } \\
\hline Weekday hours watching TV & 8 & -0.283 & -0.254 & 0.903 & 0.956 & 0.029 \\
\hline Weekend hours watching TV & 8 & -0.259 & -0.149 & 0.777 & 0.769 & 0.026 \\
\hline
\end{tabular}

Note: The source variables and their question wordings are available at Q94, Q95, Q162-68, Q174, Q186-90, Q192-8, Q208-11, Q215-29, Q231-6 and Q247-9 (http://www.data-archive.ac.uk/doc/5832/mrdoc/ pdf/5832userguide.pdf).

Source: The Cultural Capital and Social Exclusion Survey.

(CAMSIS), which represents an occupational unit's relative position within the national order of social interaction and stratification. Position is the mean CAMSIS score for all the contacts reported by a respondent, indicating the overall standing of a respondent's social network.

With regard to social mobility, we combined the respondent's and their parent's ${ }^{3}$ classes to yield a five-category trajectory variable: the stable service class (professionals and managers, also called 'salariat'), the upwardly mobile into the salariat, the downwardly mobile from the salariat, the 'other' (sideways mobile between the intermediate and the working classes), and the stable working class. This allows us to assess the social differences in socio-cultural participation between the most and the least advantaged

\section{File supplied to Li - Not for distribution}


groups as well as the specific effects for those experiencing upward and downward social mobility.

In addition to mobility trajectory, parental cultural practice and own social capital indicators, we also use a range of demographic controls, such as age, sex and health, which have been shown to have an important impact on cultural consumption (Warde et al., 2008). Health pertains to the respondent's perceived health condition (relative to age) measured in Likert scales (Q457 on page A64 on the website cited above). In the present analysis, the original codes are reversed so that higher scores indicate better health for one's age. In what follows, we report the analyses. As the mobility effects on social capital have been reported elsewhere (Li et al., 2008), we focus here on the stratification effects (mobility trajectory, parental education and cultural practice) on cultural practice and its association with social capital.

Before we proceed to the analysis, we need to explain how we constructed the variables on the domains of cultural practice. As shown in Table 2.1, 23 items of cultural practice were identified and coded as ordinal variables, with categories ranging from 2 to 8 (Column 2 of Table 2.1). As there are too many items for effective use as outcome variables, we used item response theory (IRT) modelling to obtain estimates of the underlying domains of cultural practice (Lord and Novick, 1968; Skrondal and Rabe-Hesketh, 2004). The IRT model postulates that a single continuous factor underlies responses to all items (indicators) within a set but that this factor is 'measured' subject to error in each item. A continuous score thus underlies each item, the sum of a true score contribution and an error. The distribution of this score is divided up by a set of ordered thresholds, with each section of the distribution being associated with observing one of the possible ordered categorical responses. A respondent's categorical (ordinal) score is therefore determined by their continuous score falling within a particular range of values defined by an adjacent pair of thresholds. Since the continuous score is not directly observable, it is commonly considered to be a latent variable.

Different items within a set may have different item characteristics. Items are allowed to differ in two ways. First, items may have different threshold parameters. For example, respondents may have seen more paintings in museums than they possess in their own homes. Secondly, items may have different sensitivity or factor loading parameters. This allows items to be strongly or weakly related to the underlying factor, and correspondingly to vary in the extent to which they measure the underlying factor rather than something else. Choosing a proportional odds ordinal logistic parameterization allows the model to be specified by:

$$
\ln \left(\frac{\operatorname{pr}\left(Y_{i j}<=k\right)}{\operatorname{pr}\left(Y_{i j}>k\right)}\right)=\alpha_{i K}+\lambda_{i} \eta_{j}
$$

where $Y_{i j}$ is the response to item $i$ from individual $j, \eta_{j}$ is the score of individual $j$ on the latent factor, $\lambda_{i}$ is the factor loading for item $i, \alpha_{i K}$ is the threshold for a response of $K$ or above. For an item with $K$ categories, 1 to $K, \alpha_{i K}=\infty$. Respondents with partially incomplete sets of responses were included under the assumption of the missing data being missing at random (Rubin, 1976; Muthén, 2001). Estimates of scores on the

\section{File supplied to Li - Not for distribution}


underlying factor for each individual were calculated using empirical Bayes's methods. This provided estimates both of individual scores and of estimation precision, the latter tending to be lower for those with incomplete data. Patterns of the cross-loadings (under Columns 3-5 in Table 2.1) show that the items within each set were indeed associated with a single dominant underlying latent variable.

The factor loadings and their standard errors are shown in the last two columns of Table 2.1. As we can see, most of the items in each set were fairly strongly associated with the latent structure, with correlations ranging between 0.5 and 0.9 (only 3 items having a correlation coefficient below 0.5 - belonging to art clubs, going to pubs and going to night clubs). All loadings are statistically significant at the 0.001 levels. The first factor is associated with fairly formal cultural activities such as going to the opera, visiting museums, stately homes or art galleries; the second with fairly informal and commercial activities such as going to cinemas, pubs or eating out; and the third with home-bound activities as indicated by the number of hours spent during weekdays or weekends watching TV. These broad distinctions corroborate other research using the dataset fairly closely. Thus Bennett et al. (2009) distinguish first between an engaged (our latent groups 1 and 2) and disengaged cluster (our latent group 3), and within the engaged, a distinction between the legitimate (our latent group 1) and commercial (our latent group 2) clusters (see also Warde et al., 2008).

We might note, in modified support of Bourdieu's concept of cultural capital, that cluster 1 distinguishes those engaged in cultural activities in which the state plays a role from cluster 2 where it does not. In all the items in cluster 1, with the possible exception of attendance at musicals and civic engagement, the state provides some support for the activity concerned (even the listed books may have been borrowed from state-funded libraries). In this respect, the label 'legitimate culture' is eminently deserved. On the other hand, with the possible exception of sports, the state has no role in the activities listed in the 'commercial' cluster 2.

\section{ANALYSIS}

We now move to the analysis. We first show the association between social capital and cultural practice. Then we explore the social structuring of the three domains of cultural practice. After that, we conduct multivariate and decomposition analyses to see the net effects of parental and own socio-cultural factors on the three domains of cultural practice.

Table 2.2 shows the association between socio-cultural domains. As expected, we find a reasonable degree of association, and the direction of association is also as expected. Thus the 'legitimate' and the 'commercial' practices are positively related to each other, but negatively related to TV watching, attesting to our everyday observation that people actively engaged in various forms of outdoors cultural activities spend less time at home watching TV. Secondly, all three aspects of informal social connection are positively related to legitimate and commercial practices but negatively related to TV watching. This is again expected, as people with more friends or with friends in higher and/or more diverse social positions will have more information about the higher domains of cultural practice and may conduct such activities together rather than spend hours every day

\section{File supplied to Li - Not for distribution}


Table 2.2 Correlations between cultural practice and informal social capital

\begin{tabular}{|c|c|c|c|c|c|c|c|}
\hline & & 1 & 2 & 3 & 4 & 5 & 6 \\
\hline 1 & Legitimate & 1.000 & & & & & \\
\hline 2 & Commercial & 0.515 & 1.000 & & & & \\
\hline 3 & TV watching & -0.326 & -0.427 & 1.000 & & & \\
\hline 4 & No. of social contacts & 0.266 & 0.274 & -0.179 & 1.000 & & \\
\hline 5 & Status of social contacts & 0.398 & 0.290 & -0.232 & 0.377 & 1.000 & \\
\hline 6 & Distance between contacts & 0.327 & 0.292 & -0.206 & 0.820 & 0.524 & 1.000 \\
\hline
\end{tabular}

Note: All correlations are significant at the 0.001 level.

watching TV. The findings here give evidence of a high degree of overlap between social and cultural capital, as Bourdieu (1986) argued.

Proceeding from the above, we now explore in more detail how the structural and demographic variables might determine cultural practice. Table 2.3 shows the mean scores of the three domains of cultural practice by such factors. The scores are obtained from the IRT modelling, set at a mean of zero in each domain. For ease of interpretation, we also show results of significant tests, with the scores in each category compared with the reference category (shown in italics) in each of the explanatory variables.

Table 2.3 shows strong structural but weak demographic effects. Comparing the stable salariat with the stable working class, ${ }^{4}$ we find a difference of $1.263,1.019$ and 0.873 in the three domains respectively. These are higher than the contrasts in most other variables (apart from the association between the respondent's education and commercial engagement). Interestingly, we also find that the upwardly mobile are more likely to engage in legitimate forms of cultural practices than the downwardly mobile, while the latter are more engaged in commercial cultural pursuits and TV watching. (The differences are significant in the legitimate domain and in TV viewing, $p=0.005$ and 0.026 respectively, but not so in the commercial domain, $\mathrm{p}=0.072$ ). Active participation in legitimate cultural activities may be a way to consolidate their position in the newly arrived destinations for the upwardly mobile. To be sure, the downwardly mobile still retain much from their origin classes and are not fully resigned to their destination classes in the way of cultural participation. Perhaps some of the currently downwardly mobile would aim to achieve 'counter-mobility'. This will be further assessed below when we control for a range of factors, including age, in the multivariate modelling.

We also find strong evidence that children inherit the cultural practices of their parents. Parental education and cultural participation seem more closely related to the respondent's cultural practice than even their own education, complementing previous research on the effects of the generic 'parental' cultural engagement (Scherger and Savage, 2010). By contrast with these powerful structural effects, differences associated with gender and marital status are much smaller in magnitude, although women and the partnered are more actively engaged in the legitimate practices than men or the non-partnered.

Having looked at the bivariate associations, we turn to multivariate analysis. In addition to the social capital and socio-demographic variables, we add the respondent's age,

\section{File supplied to Li - Not for distribution}


30 Handbook of research methods and applications in social capital

Table 2.3 Mean scores of cultural practice by parental and own socio-demographic attributes

\begin{tabular}{|c|c|c|c|c|}
\hline & Legitimate & Commercial & TV watching & $\mathrm{N}$ \\
\hline \multicolumn{5}{|l|}{ Mobility trajectory } \\
\hline Stable salariat & $0.709^{* * *}$ & $0.606^{* * *}$ & $-0.518 * * *$ & 208 \\
\hline Long-range upward & $0.411 * * *$ & $0.227 * * *$ & $-0.239 * * *$ & 302 \\
\hline Long-range downward & $0.205^{* * *}$ & $0.353 * * *$ & $-0.067 * * *$ & 180 \\
\hline Other & $-0.225^{* * *}$ & $-0.119 * * *$ & $0.097 * * *$ & 583 \\
\hline Stable working class & -0.554 & -0.413 & 0.355 & 291 \\
\hline \multicolumn{5}{|l|}{ Father's education } \\
\hline Tertiary & $0.857^{* * *}$ & $0.802 * * *$ & $-0.645^{* * *}$ & 113 \\
\hline Secondary & $0.219^{* * *}$ & $0.488 * * *$ & $-0.306^{* * *}$ & 250 \\
\hline Primary or none & -0.110 & -0.124 & 0.101 & 1201 \\
\hline \multicolumn{5}{|l|}{ Mother's education } \\
\hline Tertiary & $0.690^{* * *}$ & $0.660^{* * *}$ & $-0.459 * * *$ & 110 \\
\hline Secondary & $0.390 * * *$ & $0.658 * * *$ & $-0.362 * * *$ & 258 \\
\hline Primary or none & -0.134 & -0.151 & 0.096 & 1196 \\
\hline \multicolumn{5}{|l|}{ Father's cultural pursuit } \\
\hline Reading/art/classical music & $0.449 * * *$ & $0.225^{* * *}$ & $-0.200^{* * *}$ & 245 \\
\hline Cinema/sport/pop music & $0.045^{* * *}$ & $0.131 * * *$ & $-0.043^{*}$ & 587 \\
\hline Gardening/DIY/cooking & $-0.071 * *$ & $-0.003 * *$ & 0.014 & 453 \\
\hline None & -0.286 & -0.197 & 0.112 & 279 \\
\hline \multicolumn{5}{|l|}{ Mother's cultural pursuit } \\
\hline Reading/art/classical music & $0.424 * * *$ & $0.375^{* * *}$ & $-0.247 * * *$ & 230 \\
\hline Cinema/sport/pop music & $0.149 * * *$ & $0.324 * * *$ & $-0.087 * * *$ & 143 \\
\hline Gardening/DIY/cooking & $-0.009 * * *$ & $0.014 * * *$ & $-0.013^{* * *}$ & 977 \\
\hline None & -0.419 & -0.350 & 0.221 & 214 \\
\hline \multicolumn{5}{|l|}{ Respondent's education } \\
\hline Tertiary & $0.709 * * *$ & $0.562 * * *$ & $-0.453 * * *$ & 356 \\
\hline Secondary & $0.010 * * *$ & $0.211 * * *$ & $-0.076^{* * *}$ & 723 \\
\hline Primary or none & -0.534 & -0.636 & 0.412 & 485 \\
\hline \multicolumn{5}{|l|}{ Sex } \\
\hline Female & $0.097 * * *$ & $0.008^{*}$ & -0.015 & 877 \\
\hline Male & -0.076 & 0.102 & -0.036 & 687 \\
\hline \multicolumn{5}{|l|}{ Marital status } \\
\hline Partnered & $0.090 * * *$ & 0.039 & $-0.066^{*}$ & 830 \\
\hline Non-partnered & -0.108 & 0.071 & 0.048 & 733 \\
\hline
\end{tabular}

Note: Each of the other categories in a variable is contrasted with the reference category listed in italics, with the results of significance tests shown.

age squared and health status. It is noted here that even though we use social capital indicators as explanatory variables, the relationship between them and cultural practices should be regarded as being contemporaneous rather than uni-directional. This, rather than a shortcoming in the research design, is exactly what we would hold at a conceptual level, namely, that social and cultural capital domains are closely related and mutually reinforcing, and that both have powerful structural underpinnings. ${ }^{5}$

\section{File supplied to Li - Not for distribution}


Table 2.4 Regression coefficients on cultural practice by socio-demographical attributes

\begin{tabular}{|c|c|c|c|}
\hline & Legitimate & Commercial & TV watching \\
\hline \multicolumn{4}{|l|}{ Mobility class (stable working $=$ ref.) } \\
\hline Stable salariat & $0.380^{* * *}$ & $0.323^{* * *}$ & $-0.321^{* * *}$ \\
\hline Long-range upward & $0.355^{* * *}$ & $0.238 * * *$ & $-0.281 * * *$ \\
\hline Long-range downwards & $0.314 * * *$ & $0.165^{* *}$ & -0.046 \\
\hline Other & 0.096 & $0.104 *$ & -0.109 \\
\hline \multicolumn{4}{|c|}{ Father's education (primary/none $=$ ref.) } \\
\hline Tertiary & $0.192 *$ & $0.163^{*}$ & $-0.278^{* *}$ \\
\hline Secondary & 0.011 & 0.046 & $-0.125^{*}$ \\
\hline \multicolumn{4}{|c|}{ Mother's education (primary/none = ref.) } \\
\hline Tertiary & $0.338 * * *$ & 0.086 & -0.075 \\
\hline Secondary & $0.253 * * *$ & $0.146^{* *}$ & -0.061 \\
\hline \multicolumn{4}{|l|}{ Father's cultural pursuit (none $=$ ref.) } \\
\hline Reading/art/classical music & $0.226^{* * *}$ & 0.089 & -0.030 \\
\hline Cinema/sport/pop music & 0.078 & 0.043 & 0.040 \\
\hline Gardening/DIY/cooking & 0.064 & 0.030 & 0.013 \\
\hline \multicolumn{4}{|l|}{ Mother's cultural pursuit (none $=$ ref.) } \\
\hline Reading/art/classical music & $0.324 * * *$ & $0.192 * *$ & -0.100 \\
\hline Cinema/sport/pop music & $0.230 * *$ & $0.197 * *$ & -0.029 \\
\hline Gardening/DIY/cooking & 0.108 & 0.088 & -0.034 \\
\hline \multicolumn{4}{|l|}{ R's education (primary/none $=$ ref.) } \\
\hline Tertiary & $0.708 * * *$ & $0.437 * * *$ & $-0.305^{* * *}$ \\
\hline Secondary & $0.393 * * *$ & $0.304 * * *$ & $-0.197 * * *$ \\
\hline \multicolumn{4}{|l|}{ Informal social capital } \\
\hline Number of contacts & 0.013 & 0.014 & -0.002 \\
\hline Social status of contacts & $0.009 * * *$ & $0.005 * * *$ & $-0.005^{* *}$ \\
\hline Social distance between contacts & 0.003 & 0.002 & -0.002 \\
\hline Female & $0.160 * * *$ & $-0.122^{* * *}$ & 0.036 \\
\hline Partnered & 0.002 & -0.057 & -0.026 \\
\hline Age/10 & $0.466^{* * *}$ & $-0.264^{* * *}$ & -0.021 \\
\hline Age/10 squared & $-0.035^{* * *}$ & 0.008 & 0.008 \\
\hline Health & $0.069 * * *$ & $0.096 * * *$ & $-0.117^{* * *}$ \\
\hline Constant & $-2.900 * * *$ & -0.040 & $0.930^{* * *}$ \\
\hline Adj. $\mathrm{R}^{2}$ & 0.457 & 0.517 & 0.191 \\
\hline $\mathrm{N}$ & 1559 & 1559 & 1559 \\
\hline
\end{tabular}

Table 2.4 shows the coefficients on the three domains of cultural practice. The asterisks relate to the preceding coefficients and should be read as in a normal multivariate table. For instance, the stable salariat is estimated to be 0.38 points higher than the stable working class in the legitimate domain of cultural practice, and this is significant at the 0.001 level (Column 2 of Table 2.4). In addition, we also conducted tests of significance for differences between commercial and TV viewing respectively with legitimate,

\section{File supplied to Li - Not for distribution}


and between commercial and TV viewing. Significant differences (at 5 per cent level or above) between commercial and legitimate, and between TV viewing and legitimate domains for each category are shown in bold figures under the respective columns, and significant differences between commercial and TV viewing domains are shown in italic figures under the last column. Take the effects of the respondent's tertiary education, for example. The estimated coefficients for the three domains are $0.708,0.437$ and -0.305 respectively. The latter two values are both significantly lower than the first (in bold), and the third is also significantly lower than the second (in bold italics).

The data in Table 2.4 show that, with the other factors in the models held constant, the respondent's education plays the most salient role in each of the three domains of cultural practice. Yet, even with the educational effects controlled for, we still find that class matters, as do parental education, cultural pursuits and the social position of contacts, as well as gender, age and health. Another notable feature is the generally stronger impact in the legitimate domain relative to the other two. This is again as expected, since legitimate activities such as visiting museums and art galleries and attending operas and concerts are usually the preserve of the more privileged sector of society. In all structural aspects from mobility trajectory to parental education and cultural pursuits to social networks, we find a significantly stronger impact in the legitimate than in the two other domains (as shown in the emboldened figures). It is also noteworthy that, at a similar level of education and for the same kind of cultural activity, mothers seem to play a more prominent role than fathers in shaping children's cultural taste and preferences for the higher-order (legitimate) cultural practice. ${ }^{6}$

Another interesting feature that emerges from the patterns pertains to the net effects of mobility classes. We remarked on their pronounced gross differences in our discussion on the data in Table 2.3. Here we again find significant net effects among the stable salariat, the upward and downwardly mobile groups in all three domains, with clear gradients. Furthermore, and with particular attention to the two mobile groups, we find that although they are similar in the legitimate and the commercial types of cultural practice, the downwardly mobile spend a significantly greater amount of time than the upwardly mobile watching TV $(-0.046--0.281=0.235$, p. 0.003$)$. Finally, with regard to the demographic factors, we find that women and older (but not very old) respondents are more involved in the legitimate and less involved in the commercial type of cultural activity. These echo findings in an earlier study about young men frequenting pubs, night clubs, cinemas, rock concerts or eating out as an outstanding phenomenon in British culture (Warde et al., 1999). The poorly educated stable working class with friends in 'low places' participate in neither legitimate nor commercial activities in their cultural consumption, a feature little noted in the literature of cultural practice.

The data in Tables 2.3 and 2.4 have thus revealed pronounced structural effects in both gross and net terms. The effects are each significantly related to the three domains of cultural practice but do not show the relative weight at a higher level, that is, in terms of 'block' influences. For instance, are the class differences more attributable to social capital, parental heritage, education or personal attributes? In order to address this question, we need to calculate the net 'contributions'. In Table 2.5 we report results of a decomposition analysis where we differentiate four clusters of such influences. Model 1 includes social capital indicators (volume, position and range), Model 2 adds both parents' education and cultural hobbies, Model 3 further adds the respondent's

\section{File supplied to Li - Not for distribution}


Table 2.5 Decomposing differences in cultural practice between mobility classes

\begin{tabular}{|c|c|c|c|c|c|c|}
\hline & \multirow[t]{2}{*}{ Scores } & \multicolumn{4}{|c|}{$\%$ of gap explained by } & \multirow{2}{*}{$\begin{array}{l}\% \text { gap } \\
\text { residual }\end{array}$} \\
\hline & & M1 & M2 & M3 & M4 & \\
\hline \multicolumn{7}{|l|}{ Legitimate } \\
\hline Stable salariat & 0.709 & 34.8 & 31.2 & 21.9 & 4.5 & 13.6 \\
\hline Long-range upward & 0.411 & 32.5 & 9.2 & 25.7 & 12.9 & 19.7 \\
\hline Long-range downward & 0.205 & 21.3 & 42.5 & 6.9 & 3.6 & 25.7 \\
\hline Other & -0.225 & 30.3 & 18.9 & 10.4 & 20.0 & 20.4 \\
\hline Stable working class (ref.) & -0.554 & & & & & \\
\hline \multicolumn{7}{|l|}{ Commercial } \\
\hline Stable salariat & 0.606 & 31.5 & 37.9 & 16.2 & -0.5 & 14.9 \\
\hline Long-range upward & 0.227 & 36.9 & 19.9 & 31.4 & -9.6 & 21.4 \\
\hline Long-range downward & 0.353 & 21.0 & 61.7 & 9.9 & -3.8 & 11.2 \\
\hline Other & -0.119 & 33.5 & 22.0 & 21.9 & -13.4 & 26.0 \\
\hline Stable working class (ref.) & -0.413 & & & & & \\
\hline \multicolumn{7}{|l|}{ TV watching } \\
\hline Stable salariat & -0.518 & 30.7 & 36.9 & 15.7 & 1.1 & 15.0 \\
\hline Long-range upward & -0.239 & 33.0 & 13.4 & 30.1 & -0.9 & 24.4 \\
\hline Long-range downward & -0.067 & 24.2 & 59.7 & 12.0 & -1.0 & 5.1 \\
\hline Other & 0.097 & 19.5 & 20.2 & 13.6 & 7.2 & 39.4 \\
\hline Stable working class (ref.) & 0.355 & & & & & \\
\hline
\end{tabular}

education, and Model 4 adds the respondent's personal attributes (gender, age, marital status and health status). As our outcome variables are continuous, we use the Blinder-Oaxaca method (Blinder, 1973; Oaxaca, 1973).

We are interested here in the cluster effects in the cultural practice. Under Column 2 of Table 2.5, we copy the mean scores for each domain of cultural practice for the mobility groups from Table 2.3. Take the legitimate form of cultural practice for example. There is a difference (gap) of $(0.709--0.554=) 1.263$ between the stable salariat and the stable working class. Similarly, the gap in TV viewing is $(0.355--0.518=) 0.873$. The figures under the four models are the percentages of the gaps explained by each of the clusters of influences in net terms. Thus we find that in each of the three cultural domains, social capital explains around 31-35 per cent of the differences between the stable salariat and the stable working class, inheritance explains a bit more, 31-38 per cent, and education explains a further 16-22 per cent. All this demonstrates the unique importance of social capital and parental cultural capital in explaining the differences between the most and the least advantaged social groups in their cultural participation.

Turning to the two mobile groups, we find some interesting differences. Social capital assumes a notably more pronounced role for the upwardly than for the downwardly mobile group, around 10-15 percentage points more in the three domains, which is actually (albeit slightly) more salient than that between the stable salariat and the downwardly mobile. Parental cultural capital makes a strong contribution to the downwardly mobile's cultural practice, accounting for 43-62 per cent of the difference with the stable working class. Education plays the most important role for the upwardly mobile, much

\section{File supplied to Li - Not for distribution}




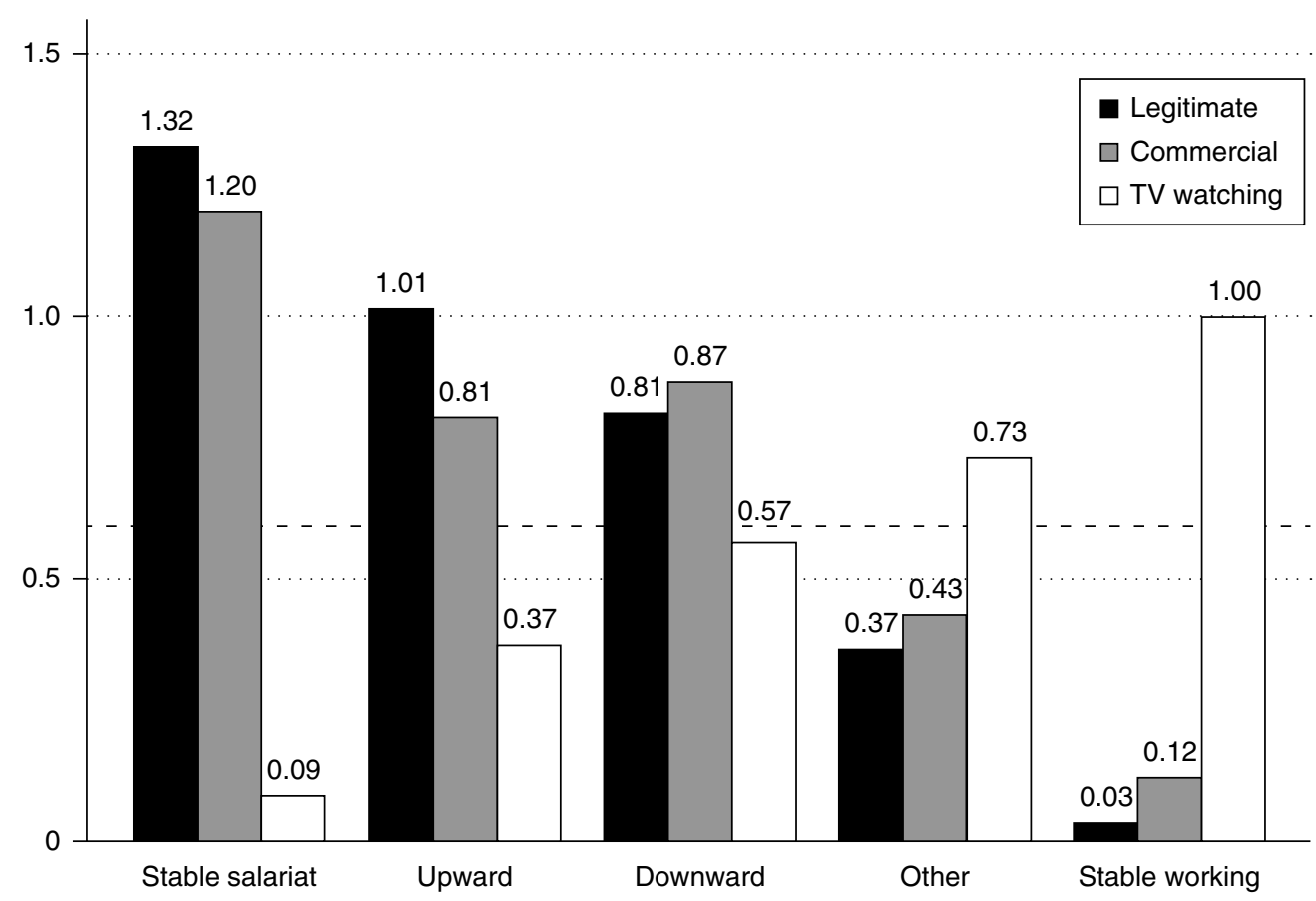

Note: Predicted values +0.6 , controlling for all other variables in the models in Table 2.4.

Figure 2.1 Net mobility effects on cultural practice

higher than for the stable salariat or for the downwardly mobile group. The patterns thus show that the main resources for the stable salariat are parental cultural capital and own social capital, those for the upwardly mobile are their social capital and education, and those for the downwardly mobile are predominantly their parental cultural resources. Personal characteristics play a very limited role after controlling for social capital, parental heritage and education, although the effects on the upwardly mobile in the legitimate domain are noticeable. ${ }^{7}$

Finally in this section, we show, with a view for the overall picture, the net class differences in the three domains of cultural practice (Figure 2.1). The data are derived from the models in Table 2.4 with the values of all covariates set at their means. As each domain has a mean score of zero, a class may have negative values in one or another domain. We thus added a value of 0.6 to each bar in the figure for ease of exposition. A clear pattern is revealed with the combination of cultural engagement in monotonic relationship to social mobility trajectory. The cultural practice of the stable salariat is concentrated in the legitimate and commercial domains, and they spend the least amount of time watching TV. The stable working class, by contrast, engage little in legitimate or commercial activities and are more likely to be heavy users of television. The evidence is consistent with both a Bourdieusian claim that the more privileged classes are distinguished by their attachments to legitimate culture and the omnivore thesis that in the twenty-first century

\section{File supplied to Li - Not for distribution}


those with highest socioeconomic status will combine popular (or here commercial) practices with legitimate preferences.

\section{DISCUSSION AND CONCLUSION}

In this chapter we have sought to demonstrate the structural underpinnings of cultural practice in contemporary British society. We have shown that class matters and that cultural resources transmitted by parents are part of the constitution of class membership.

People's social networks are also closely related to the kind of cultural practice they adopt. In this regard, we find that social contacts' positions are more closely related to people's cultural practice, the legitimate kind in particular, than the volume or the diversity (range), although all three aspects of informal social capital are significantly associated with the three domains in the gross effects. Even controlling for many other structural factors, we still find a highly significant association between social contacts' position and one's own cultural practice. This arises partly because people derive awareness and knowledge of standards about cultural activities from their interaction with others. Since friends in 'higher places' tend to engage in legitimate forms of cultural consumption, it is little wonder that the social position of one's social ties is positively associated with activities like visiting theatres, art galleries, museums or stately homes. Furthermore, we find that social capital plays a much more salient role for the stable salariat and the upwardly mobile than for the downwardly mobile.

Apart from family class and people's social connection, we also find a very important role of parental education and cultural practice. Cultural capital as a concept is most closely associated with Bourdieu (1984) but even in his own analysis he only used parental education as an indicator. In British research, Scherger and Savage (2010) used the generic 'parental' practice. Ours is arguably the first research study that assesses the impacts of both parents' education and cultural pastimes on cultural consumption, and it is very remarkable that they play a highly significant role, even controlling for the respondent's own education and other characteristics. Furthermore, we find that parental practice impacts most strongly on the downwardly mobile and least on the upwardly mobile. Here our analysis provides a first national-level picture of cultural inheritance.

The establishment of three domains of cultural practice from a wide range of indicator variables is itself an important finding. The indicators are strongly correlated with the underlying latent structures, which gives us considerable reassurance about the structuring of types of cultural practice prevalent in contemporary British society. The existence of a legitimate and a commercial form of cultural practice gives modified support for Bourdieu's emphasis on the distinctiveness of a kind of cultural capital linking particular predispositions to legitimate activities.

The fact that those in the highest social class like swathes of commercial culture (once described as middlebrow) has obscured the continued dominance of high culture by the professional-managerial class, and by the second-generation salariat in particular. This is complementary evidence for the cultural omnivorousness thesis since the class does exhibit diverse and extensive cultural engagement, combining tastes for legitimate and popular domains of cultural practice. As Peterson (2005) noted, recent studies have tended to concentrate solely on volume of commitment, partly because it is easier to

\section{File supplied to Li - Not for distribution}


obtain such data. However, by taking advantage of latent structural analysis through the use of the item response theory modelling, it is possible to construct a more robust indicator of taste cultures than was available in the seminal article of Peterson and Kern (1996) or in much of the subsequent work on omnivorousness. Consequently, this analysis provides strong grounds for favouring explanations of cultural practice in which class distinctions are primarily manifested in the legitimate domain and then, to a lesser degree, in a combination of both legitimate and common domains (a privileged combination of omnivorousness). The inappropriateness of an interpretation in terms of a benevolent omnivorousness in denial of the continued existence of sharp class divisions is made clear by considering the differences between the stable salariat and the stable working-class respondents. That, it seems to us, would be to miss the crucial point of social stratification in contemporary UK.

Overall, we found clear differences across the three forms of cultural practice associated with intergenerational mobility, social capital, parental education and cultural preferences, and the respondent's education. Demographic attributes, especially those of gender and marital relations, do not have marked impacts on cultural practice though women tend to have a slightly greater propensity for participation in legitimate culture. Classes polarize. The stable salariat and the stable working class stand at opposite ends, especially in the legitimate and the TV viewing domains. Visiting museums, stately homes and art galleries, going to operas, classical concerts, theatres and art clubs, possessing paintings or reading books are predominantly the preserve of those in the most advantaged class positions, especially the secondgeneration salariat. Also, social connections, friends in higher places, and parental education and cultural pursuits play a distinct role, so privilege generates further privilege.

The deeply entrenched class differences in cultural practice lead us to dismiss strong versions of postmodernist or individualization theses, and their corollaries that taste cultures no longer divide significant and substantial segments of the population. Furthermore, our analysis shows that class is associated with taste independently of education, age, gender, marital status or social networks. We are thus able to show that class does affect cultural consumption, doing so not only by intensity of engagement but also by preference for legitimate activities.

Our analysis therefore demonstrates important relationships between different measures of cultural, economic and social assets - of both parents and respondents - and shows that cultural practices remain structured. The domain of cultural practice has not become a level playing field. Moreover, the structuring of these domains is complex and not readily reducible to a unitary measure of social inequality. Rather, the interplay between parental and respondents' characteristics deserves close scrutiny. Although our evidence relates only to Britain, it seems likely that it will apply to other post-industrial societies. To the extent that most have, on standard measures of cultural omnivorousness, shown great similarities in the patterning of socio-demographic characteristics and degrees of eclecticism in taste, it remains possible, and in our view highly likely, that the distinguishing feature of omnivores is their retention of elements of legitimate culture whilst extending outward for popular culture yet still avoiding some of the least distinguished activities like heavy TV viewing. It is thus premature to announce the death of class in the cultural realm. Our findings also give some substantiation to qualitative

\section{File supplied to Li - Not for distribution}


studies which have never ceased to record the hidden injuries of class at the level of cultural judgement and everyday social experience.

\section{NOTES}

1. For instance, the CCSE has richer details on cultural taste, cultural knowledge and cultural practice than those found in the Arts in England Survey (2001) conducted by the Office of National Statistics on behalf of the Arts Council England on the basis of which much recent inquiry into cultural life has been made. It also has much detail on parental education and cultural preferences that few other surveys have.

2. The question reads: 'On this card is a list of jobs. Please tell me whether you happen to know anyone socially who has any of these jobs. Please include friends and relatives.'

3. 'Parent' is defined as the main household earner when the respondent was aged between 14 and 16 . The class trajectory variable is constructed using parent's and respondent's classes shown below.

\begin{tabular}{llll}
\hline & \multicolumn{2}{c}{ Respondent's class } \\
\cline { 2 - 4 } & Salariat & Intermediate & Working class \\
\hline Parental class & Stable salariat & Downwardly mobile & Downwardly mobile \\
Salariat & Upwardly mobile & Other & Other \\
Intermediate & Upwardly mobile & Other & Stable working class \\
Working class & Upwal & \\
\hline
\end{tabular}

4. We also conducted separate analysis of parental and own class on the three domains. People from salariat origins or in salariat positions are significantly more likely to conduct legitimate and commercial types of cultural practice than their working-class counterparts ( 0.77 and 0.70 higher $)$, while the opposite is true in terms of TV viewing ( 0.494 lower). Similarly, the respondent's own class position also has a significant impact, with the salariat lead over the working class being 0.89 and 0.58 in legitimate and commercial domains, and the working class lead in TV watching being 0.59 .

5. Further analysis using multivariate regression attests to the mutual impact of the social and cultural capital domains.

6. We compared the net effects of parental education and hobbies using the Wald test $\left(t=\left(b_{1}-b_{2}\right) /\left(s_{1}^{2}+s_{2}^{2}\right)^{1 / 2}\right)$. The results show that, other things being equal, mothers with secondary education have a significantly greater impact on the respondent's legitimate cultural practice than fathers with the same level of education $(\mathrm{p}=0.006)$. The other contrasts are not significant at the conventional level.

7. Further analysis finds that the upwardly mobile are similar to the other groups in terms of age, health and gender but are most likely to be married, at 73.5 per cent, as compared with 57.3 per cent for the stable working class. Maybe this contributes to their greater participation in legitimate cultural practice. Marriage is, after all, considered one of the best forms of social capital by some scholars (Putnam, 2000).

\section{REFERENCES}

Atkinson, W. (2010), In Search of the Reflexive Worker, Basingstoke: Palgrave.

Ball, S. (2003), Class Strategies and the Education Market Place, London: RoutledgeFalmer.

Bauman, Z. (1998), Globalisation: the Human Consequences, Oxford: Blackwell.

Beck, U. (1992), Risk Society: Towards a New Modernity, London: Sage.

Beck, U. (1997), The Reinvention of Politics: Rethinking Modernity in the Global Social Order, Cambridge: Polity Press.

Bennett, T., M. Gayo-Cal, M. Savage, E. Silva, A. Warde and D. Wright (2009), Culture, Class, Distinction, London: Routledge.

Blinder, A.S. (1973), 'Wage Discrimination: Reduced Form and Structural Estimates', The Journal of Human Resources, 8: 436-55.

Bourdieu, P. (1984), Distinction: A Social Critique of Taste, Cambridge, MA: Harvard University Press.

Bourdieu, P. (1986), 'The Forms of Capital', in J.G. Richardson (ed.), Handbook of Theory and Research for the Sociology of Education, New York: Greenwood.

\section{File supplied to Li - Not for distribution}


Bourdieu, P. (1987), 'What Makes a Social Class? On the Theoretical and Practical Existence of Groups', Berkeley Journal of Sociology, 32: 1-17.

Bourdieu, P. and J. Passeron (1973), Reproduction in Education, Society and Culture, London: Sage.

Bulmer, M. (1975), Working-Class Images of Society, London: Routledge and Kegan Paul.

Chan, T. and J.H. Goldthorpe (2007), 'Class and Status: The Conceptual Distinction and its Empirical Evidence', American Sociological Review, 72: 512-32.

Charlesworth, S. (2000), A Phenomenology of Working-Class Experience, Cambridge: Cambridge University Press.

Coleman, J. (1990), Foundations of Social Theory, Cambridge, MA: Harvard University Press.

Crompton, R. (1998), Class and Stratification, 2nd edn, Oxford: Blackwell.

Cultural Capital and Social Exclusion: A Critical Investigation (2003/2005), available at: http://discover. ukdataservice. ac.uk/catalogue/?sn=5832\&type $=$ Data\%20catalogue, accessed on 1 December 2013.

Devine, F. and Y. Li (2013), 'Social Mobility and the Changing Relationship between Origin, Education and Destination', British Journal of Sociology of Education, 34(5-6): 766-91.

Erickson, B. (1996), 'Culture, Class and Connections', American Journal of Sociology, 102(1): 217-51.

Erikson, R. and J.H. Goldthorpe (1992), The Constant Flux, Oxford: Clarendon Press.

Fiske, J. (1989), Understanding Popular Culture, London: Routledge.

Giddens, A. (1991), Modernity and Self-Identity: Self and Society in the Late Modern Age, Cambridge: Polity Press.

Goldthorpe, J.H. (with C. Llewellyn and C. Payne) (1987), Social Mobility and Class Structure in Modern Britain, Oxford: Clarendon Press.

Goldthorpe, J.H. and C. Mills (2008), 'Trends in Intergenerational Class Mobility in Modern Britain: Evidence from National Surveys', National Institute Economic Review, 205: 83-100.

Hall, P. (1999), 'Social Capital in Britain', British Journal of Political Science, 29: 417-61.

Hebdige, D. (1979), Subculture, or the Meaning of Style, London: Routledge.

Lamont, M. and A. Lareau (1988), 'Cultural Capital: Allusions, Gaps and Glissandos in Recent Theoretical Developments', Sociological Theory, 6: 153-68.

Lash, S. and J. Urry (1987), The End of Organized Capitalism, Cambridge: Polity Press.

Le Roux, B., H. Rouanet, M. Savage and A. Warde (2008), 'Class and Cultural Division in the UK', Sociology, 42(6): 1049-71.

Li, Y. and F. Devine (2011), 'Is Social Mobility Really Declining? Intergenerational Class Mobility in Britain in the 1990s and the 2000s', Sociological Research Online, available at: http://www.socresonline.org. uk/16/3/4.html.

Li, Y. and F. Devine (2014), 'An Analysis of Social Mobility in Britain, 1991-2011', in L. Archer, A. Mann and J. Stanley (eds), Understanding Employer Engagement in Education: Theories and Evidence, Abingdon: Routledge, pp. 79-91.

Li, Y., A. Pickles and M. Savage (2005), 'Social Capital and Social Trust in Britain', European Sociological Review, 21(2): 109-23.

Li, Y., M. Savage and A. Pickles (2003), 'Social Capital and Social Exclusion in England and Wales 1972-1999', British Journal of Sociology, 54(4): 497-526.

Li, Y., M. Savage and A. Warde (2008), 'Social Mobility and Social Capital in Contemporary Britain', British Journal of Sociology, 59(3): 391-411.

Lin, N. (2001), Social Capital, Cambridge: Cambridge University Press.

Lockwood, D. (1966), 'Sources of Variation in Working Class Images of Society', Sociological Review, 14(3): 249-67.

Lord, F.M. and M.R. Novick (1968), Statistical Theories of Mental Test Scores, Reading, MA: Addison-Wesley.

Muthén, B. (2001), 'Latent Variable Mixture Modeling', in G.A. Marcoulides and R.E. Schumacker (eds), New Developments and Techniques in Structural Equation Modeling, Mahwah, NJ: Lawrence Erlbaum Associates.

Oaxaca, R. (1973), 'Male-female Wage Differentials in Urban Labor Markets', International Economic Review, 14: 693-709.

Pakulski, J. and M. Waters (1996), The Death of Class, London: Sage.

Peterson, R. (1997), 'The Rise and Fall of Highbrow Snobbery as a Status Marker', Poetics, 25: 75-92.

Peterson, R. (2005), 'Problems in Comparative Research: The Example of Omnivorousness', Poetics, 33: 257-82.

Peterson, R.A. and R.M. Kern (1996), 'Changing Highbrow Taste: From Snob to Omnivore', American Sociological Review, 61(5): 900-907.

Prieur, A. and M. Savage (2011), 'Updating Cultural Capital Theory: A Discussion Based on Studies in Denmark and in Britain', Poetics, 39(6): 566-80.

Putnam, R. (2000), Bowling Alone: The Collapse and Revival of American Community, New York: Simon \& Schuster.

\section{File supplied to Li - Not for distribution}


Robbins, D. (2005), 'The Origins, Early Development and Status of Bourdieu's Concept of "Cultural Capital”, British Journal of Sociology, 56(1): 13-29.

Rubin, D. (1976), 'Inference and Missing Data', Biometrika, 63: 581-92.

Savage, M. (2000), Class Analysis and Social Transformation, Milton Keynes: Open University Press.

Savage, M. and K. Williams (2008), 'Elites: Remembered in Capitalism and Forgotten by Social Sciences', in M. Savage and K. Williams (eds), Remembering Elites, Oxford: Blackwell, pp. 1-24.

Savage, M., B. Bagnall and B. Longhurst (2001), 'Ordinary, Ambivalent and Defensive: Class Identities in the North West of England', Sociology, 35(4): 875-92.

Savage, M., M. Gayo-Cal, A. Warde and G. Tampubolon (2005), 'Cultural Capital in the UK: A Preliminary Report Using Correspondence Analysis', CRESC Working Papers on Socio-Cultural Change, No. 4, University of Manchester and the Open University.

Savage, M., F. Devine, N. Cunningham, M. Taylor, Y. Li, J. Hjellbrekke, B. Le Roux, S. Friedman and A. Miles (2013), 'A New Model of Social Class? Findings from the Great British Class Experiment', Sociology, 47(2): 219-50.

Scherger, S. and M. Savage (2010), 'Cultural Transmission, Educational Attainment and Social Mobility', The Sociological Review, 58(3): 406-28.

Silva, E. and A. Warde (eds) (2010), Cultural Analysis and the Legacy of Bourdieu: Settling Accounts and Developing Alternatives, London: Routledge.

Skeggs, B. (1997), Formations of Class and Gender, London: Sage.

Skeggs, B. (2004), Class, Culture, Self, London: Routledge.

Skrondal, A. and S. Rabe-Hesketh (2004), Generalized Latent Variable Modelling: Multilevel, Longitudinal, and Structural Equation Models, Boca Raton, FL: Chapman and Hall/CRC.

Sorensen, A. (2000), 'Employment Relations and Class Structure', in R. Crompton, F. Devine, M. Savage and J. Scott (eds), Renewing Class Analysis, Oxford: Blackwell.

Southerton, D. (2002), 'Boundaries of "Us" and "Them": Class, Mobility and Identification in a New Town', Sociology, 36(1): 171-93.

Thomson, K. (2004), Cultural Capital and Social Exclusion Survey: Technical Report, London: National Centre for Social Research.

Warde, A. (2011), 'Cultural Hostility Re-visited', Cultural Sociology, 5(3): 341-66.

Warde, A., L. Martens and W. Olsen (1999), 'Consumption and the Problem of Variety: Cultural Omnivorousness, Social Distinction and Eating Out', Sociology, 33: 105-27.

Warde, A., D. Wright and M. Gayo-Cal (2008), 'The Omnivore Orientation in the UK', Poetics, 36: 148-65.

Wilkinson, R. and C. Pickett (2009), The Spirit Level, London: Allen Lane.

Willis, P. (1977), Learning to Labour: How Working Class Kids get Working Class Jobs, Farnborough, UK: Saxon House.

\section{File supplied to Li - Not for distribution}

